\title{
Circadian and lunar gamete release in Fucus vesiculosus in the atidal Baltic Sea
}

\author{
Sylvia Andersson ${ }^{1}$, Lena Kautsky ${ }^{2}$, Arja Kalvas ${ }^{2}$ \\ ${ }^{1}$ Department of Systems Ecology, ${ }^{2}$ Department of Botany, Stockholm University, S-106 91 Stockholm, Sweden
}

\begin{abstract}
Released eggs from Fucus vesiculosus were counted every 12 or $4 \mathrm{~h}$ in the field and every $24 \mathrm{~h}$ in laboratory experiments at constant temperature and a $17 \mathrm{~h}$ light: $7 \mathrm{~h}$ dark cycle, mimicking natural light conditions. A fortnightly rhythm was confirmed both in the field and in controlled laboratory studies, with a main egg release $2 \mathrm{~d}$ before full and new moon, but with indication of a minor weekly period of unequal amplitude. The highest daily release of eggs was typically found from 18:00 to $22: 00 \mathrm{~h}$. Dehydration was not found to influence the pattern of egg release and in the field no correlation was found with temperature or water level fluctuations. An endogenous clock in $F$. vesiculosus is suggested and different entraining factors presented and discussed. We further suggest that the observed rhythmicity is of great adaptive value for coordination of gamete release in a dioecious species like $F$. vesiculosus in the atidal environment of the Baltic Sea, where this species occurs almost always submerged. Ecologically, the cyclic gamete release means that reproduction and recruitment are reduced to a few occasions during the reproductive period, which was earlier assumed to be several months long. This information may be crucial in the successful management of this ecologically important species in the Baltic Sea which has been severely reduced in abundance in recent decades due to pollution.
\end{abstract}

KEY WORDS: Baltic Sea - Fucus vesiculosus - Seaweed - Reproduction - Rhythmicity - Lunar cycle · Circadian cycle - Gamete release

\section{INTRODUCTION}

Fucus vesiculosus $\mathrm{L}$. is the only widespread, large perennial seaweed in the Baltic Sea where it dominates the biomass (Jansson \& Kautsky 1977, Kautsky 1988) and is the base of the most diverse hard-bottom community with some 30 species of macrofauna and epiflora (Haage 1975, Kautsky et al. 1992). Reduction in the distribution of the Baltic $F$. vesiculosus population (Kangas et al. 1982, Lindvall 1984, Mäkinen et al. 1984, Rönnberg 1984, Kautsky et al. 1986, 1992) has made it urgent to study factors governing the reproduction, recolonization potential and survival of this seaweed. Studies on the age and size structure of $F$. vesiculosus populations from a wave exposure gradient (Kalvas \& Kautsky 1993) and those in a pulp mill effluent area (Kautsky 1992, Kautsky et al. 1992) showed that factors like wave exposure, pollution and grazing pressure are all important for the size structure and possible reproductive success of new germlings.
The mean size of $F$, vesiculosus plants at first reproduction has been shown to be about $25 \mathrm{~cm}$ in the area around the Askö laboratory (Stockholm University), Sweden (Kautsky et al. 1992).

In the northern Baltic proper, reproduction of Fucus vesiculosus occurs mainly in June and July, while Carlson (1990) reported a longer reproductive period in the southern part of the Baltic Sea, with 2 peaks. The initiation of receptacles in this dioecious species starts in mid-October in the northern Baltic proper after the plants have been exposed to a short-day stimulus for 2 wk (Bäck et al. 1991). The receptacles remain dormant over winter until the ice-melt in April (Bäck et al. 1991). In ripe condition they contain oogonia with 8 eggs each or antheridia with 64 spermatozoids.

Rhythmicity of varying period length has been reported for reproductive activity, i.e. gamete release, in several algal populations, e.g. in different Derbesia spp. (Halicystis) gametophytes (see Ziegler Page \& Kingsbury 1968), in Ulva lobata (Kützing) Setchell \& 
Garder (Smith 1947), Enteromorpha intestinalis (L.) Link (Christie \& Evans 1962, Pringle 1986), Laminaria saccharina (L.) Lamour. (Lüning 1981), in the dioecios brackish Fucus cernoides L. and in different red algae (Umamaheswara \& Kaliaperumal 1987). Although observations on some of these intertidal seaweeds indicate the action of a lunar-related biological clock, there is little experimental evidence. In a recent review on the ecological perspectives of sexual reproduction in algae, Brawley \& Johnson (1992) summarize the various factors which have been suggested to affect gamete release in macroalgae in relation to a lunar or semilunar cycle. In Dictyota (reviewed by Sweeney 1987) an endogenous rhythm has been demonstrated in which moonlight is suggested as one of the presumed timekeepers.

In some species, gametes are known to be shed in response to changes in light. In most such cases release occurs at daybreak (Ziegler Page \& Kingsbury 1968, Burr \& West 1970). In contrast, eggs in Laminaria spp. (Lüning 1981) and gametes in Pelvetia fastigiata (J. G. Agardh) (Jaffe 1954) have been shown to be released at the onset of a dark cycle in laboratory experiments. Most effects of illumination on gametes have been studied in the laboratory. In the field, gamete release has been observed in UIva lobata in morning high tides (see Smith 1947) and in Fucus ceranoides largely in daytime high tides (Brawley 1992).

Other factors that might be required or that stimulate gamete release are a change in salinity (Brawley 1992), replacing of the culture medium with fresh medium (La Claire \& West 1978) or specific temperatures (Bacon \& Vadas 1991). However, factors shown in laboratory studies to be of importance for gamete release do not always appear particularly important in the field. For example, Pelvetia fastigiata may shed gametes when receptacles are placed in darkness after photoinduction (Jaffe 1954), or gamete release by Sargassum muticum (Yendo) Fensholt may be influenced by temperature in laboratory studies, but the semilunar cycle or other factors appear to have more influence on this event in the field (Brawley \& Johnsson 1992 and references therein). In earlier laboratory experiments with Baltic Fucus vesiculosus (Andersson et al. 1992), we observed a tendency for gametes to be released in the evenings at fortnightly intervals.

It is most likely that Fucus vesiculosus immigrated into the Baltic Sea from the Atlantic less than $3000 \mathrm{yr}$ ago, when salinities became tolerable. At the same time it moved from a tidal to an atidal environment and from a littoral to a sublittoral habitat. There are no reports about tidal or fortnightly rhythmicity in seaweeds living in atidal environments such as the Baltic Sea, and it would be of great interest from a genetic as well as from an ecological point of view if such a rhythm could be documented.

\section{MATERIAL AND METHODS}

The experiments in the Baltic Sea were carried out at the Askö laboratory (Stockholm University) in the northern Baltic proper. Although there are extremely small tides of only $0.05 \mathrm{~m}$ in the Baltic Sea, the water level may fluctuate irregularly by some meters over the year due to changes in barometric pressure and onand offshore winds. The salinity was low and stable in both the field and the laboratory experiments, about $6.5 \%$.

The experiments were performed in 1992. Male and female Fucus vesiculosus individuals were marked in the field and receptacles were collected from these plants each day. Twelve ripe, even-sized female and male receptacles were collected, with a mean $( \pm \mathrm{SD}$ ) number of conceptacles per receptacle of $169 \pm 12$. One male and one female receptacle were placed together in small $(20 \mathrm{ml})$ transparent plastic containers with $10 \mathrm{ml}$ of seawater. Three receptacles were replaced each day. The plastic containers were put in the field, floating in a transparent plastic bag at the surface within a larger $F$. vesiculosus stand. Temperature was measured in the $F$. vesiculosus stand as well as in the plastic containers at the sampling time, when water was changed. The water level fluctuation was recorded each day at 10:00 h. The experiment was run daily from 28 May (the start of the main reproductive season, 1992) until 16 July (near the end of the reproductive season). The water was replaced daily at 10:00 and 22:00 h. Starting from $4 \mathrm{~d}$ before each full and new moon, water containing released eggs and oogonia was sampled at shorter intervals, usually every $4 \mathrm{~h}$. Insolation, measured as $\mathrm{kJ} \mathrm{m}^{-2}$, was continuously recorded and calculated for each $4 \mathrm{~h}$ and $24 \mathrm{~h}$ period. The water samples were brought to the laboratory, fixed with Lugol solution, and the number of eggs and oogonia released were counted in an inverted microscope at $200 \times$. The total number of eggs released per receptacle was determined by multiplying the number of oogonia by 8 after which the mean number of eggs released per conceptacle $\times 100$ per day was calculated. The calculation per conceptacle was performed to reduce the effect of differences in size and number of conceptacles per receptacle.

The second experiment was performed under controlled conditions in the laboratory. The receptacles were not replaced during this experiment. They were kept in the same kind of plastic containers as in the field experiment, each container with 1 female in $10 \mathrm{ml}$ 
of filtered seawater. In this experiment, 10 receptacles from 5 different female plants were collected, 2 receptacles from each plant. The receptacles were kept cold on ice during the transportation (about $1 \mathrm{~h}$ ) to the laboratory. Five receptacles, 1 from each plant, were placed directly into the containers. Five other receptacles were put to dehydrate on moist paper overnight (for details about treatment, see Andersson et al. 1992). The water was sampled each afternoon and the number of released eggs was counted as described above. To eliminate the 'background noise' in egg release between peaks, the individual mean number of eggs released per day during the experiment (mEi) was calculated for each receptacle. The individual daily reproductive activity $(d A c)$ for each receptacle was calculated as the ratio of eggs released each day ( $d E i)$ to $m E i$. Mean reproductive activity was calculated as the sum of $d A c$ divided by the number of receptacles. Values exceeding 1.0 were considered as shedding activity. Calculations were made for control and dehydrated receptacles respectively. Egg release was counted from 6 July to 29 July at a constant temperature of $11 \pm 1^{\circ} \mathrm{C}$ and a constant light:dark regime of $17: 7 \mathrm{~h}$, which mimics the natural light conditions during the reproductive period under which the field experiments were carried out. The receptacles were accidentally exposed to light for a few minutes during the night of 8 July. The material was treated statistically ( $t$-test and linear regression) using the Statgraphics computer program.

\section{RESULTS}

A circadian rhythm was shown for egg release in the field (Fig. 1) with a peak somewhere between 18:00 and 22:00 $\mathrm{h}$ in the evening just before dark. A fortnightly rhythm was confirmed as well (Fig. 2C) with the main egg release occurring on 30 May, 13 and 28 June and on 12 July 1992. Furthermore, although the amplitude declines after the peak of the season, the eggs are mainly released $2 \mathrm{~d}$ before full (15 June, 14 July) and new (1 June, 30 June) moon. Similar to what is suggested for Laminaria saccharina (Lüning 1981), the declining amplitude might be due to a decreasing number of conceptacles contributing to the egg release reaction with time. Although receptacles were studied under the microscope at intervals during the reproductive period and the number of oogonia varied between conceptacles, empty conceptacles were never observed. Ripe oogonia were not counted but were present during the whole season, without observed periodicity. An unexpected high peak in egg release was observed at the first quarter of the moon, on 8 June but, unlike the situation in the laboratory (see

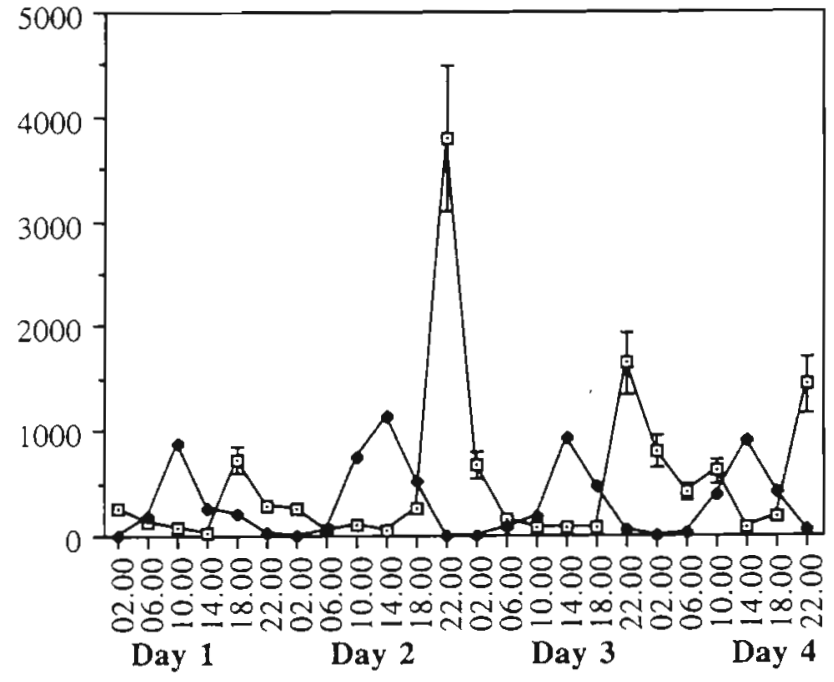

Fig. 1. Fucus vesiculosus. (四) Mean ( \pm SE) number of eggs released per receptacle every $4 \mathrm{~h}$ in the field. ( ) Insolation $\left(\mathrm{kJ} \mathrm{m}^{-2} 4 \mathrm{~h}^{-1} \times 0.1\right)$ during 11 to 14 June 1992

below), this behaviour was not repeated. Some of the large variation is thought to be due to difficulties in collecting receptacles which contained similar amounts of ripe oogonia, even if care was taken to collect evensized receptacles and the mean ( \pm SD) number of conceptacles per receptacle did not vary very much $(169 \pm 12)$.

During the investigated period the water level fluctuated from $-0.4 \mathrm{~m}$ below mean water level to $-0.05 \mathrm{~m}$ with an unusually low low-water period from May to mid-June (Fig. 2B). Temperature in the surface water also fluctuated between 14 and $25^{\circ} \mathrm{C}$, reaching the highest temperatures in the Fucus vesiculosus stand within the containers, where little water movement occurs during sunny, calm days (Fig. 2A). During late May and early June the largest temperature differences occurred between the surrounding water in the $F$. vesiculosus stand and in the containers holding the receptacles (Fig. 2A).

No linear correlation was found in the field between egg release per conceptacle and water temperature either in the surface water or in the containers holding the receptacles $\left(r^{2}=0.00\right.$ and 0.10 respectively). Similarly, no correlation was found between the sometimes drastic changes in water level between days and the release of eggs $\left(r^{2}=0.002\right)$.

For some unknown reason, possibly the accidental interruption of the dark period in the laboratory experiment, the first expected peak of egg release before full moon (14 July) was late, i.e. on the day of the full moon, and low in amplitude (Fig. 3) and the activity was higher than expected on 18 July. There were also minor peaks of activity on 7,8 and 22 July. These minor 

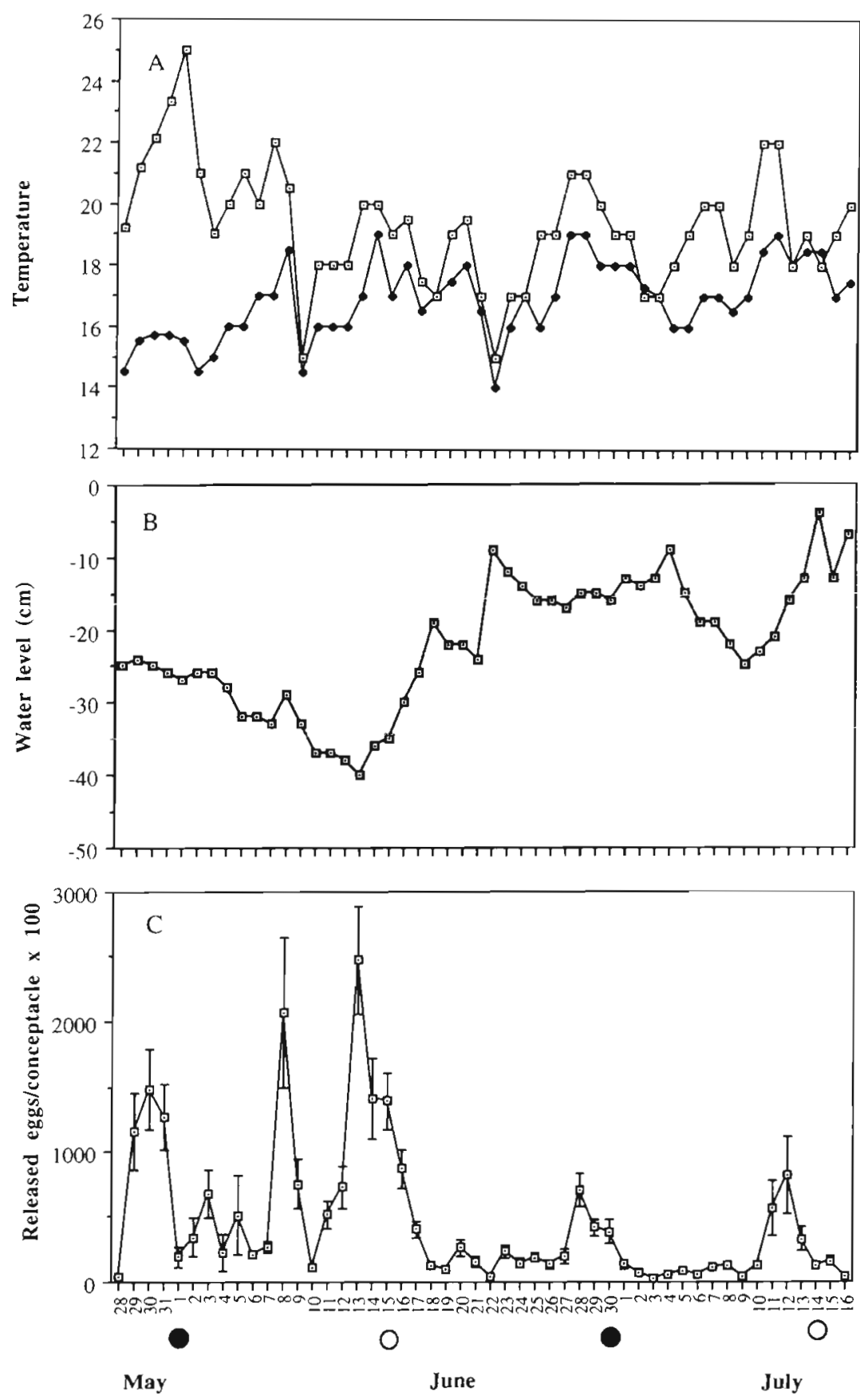

Fig. 2. Fucus vesiculosus. (A) Temperature $\left({ }^{\circ} \mathrm{C}\right)$ changes in the surface water near the $F$. vesiculosus stand $(\bullet)$ and in the container holding the receptacles ( $\square$ ) measured at 10:00 h. (B) Changes in water level $(\mathrm{cm})$ recorded at 10:00 h every day during the investigated period (28 May to 16 July 1992). (C) Mean ( \pm SE) number of eggs released per conceptacle $\times 100$ per $24 \mathrm{~h}$ in the field. Dates of full and new moon are indicated

peaks near the first and last quarter of the moon were noticed in laboratory experiments in 1990 and 1991 as well (Andersson pers. obs.), although they were small enough to be considered as 'noise' in relation to the major peaks which occurred before full and new moon.
Thus, the periodicity in the laboratory experiments of 1992 appears to be weekly, but of varying amplitude. Similarly, biweekly release has been observed in field populations in 1993 (authors' unpubl. data) although this was only indicated on 1 occasion in the field experiment in 1992, on 8 June. It is interesting to notice that the receptacles in the laboratory show the same behaviour as those in the field experiment with the major peak occuring $2 \mathrm{~d}$ before new moon on 27 July. These minor and major events occurred on the same day in dehydrated and hydrated receptacles.

Since cyclic release was observed in the Baltic Sea and, furthermore, the peaks of activity occurred on the same day for treated and untreated receptacles in the laboratory, the laboratory procedure cannot be considered to induce the rhythmicity.

\section{DISCUSSION}

A cyclic process might be driven by a rhythmic change in the environment or it might involve the action of an internal timekeeper, a biological clock. In case of external causes of rhythmicity, the periodicity will not be present under constant conditions while a cyclic process due to an endogenous timekeeper will persist, at least for some time, with a free running period. (For terminology and clock theory, see Palmer 1974, Sweeney 1977, Salisbury \& Ross 1985.) Although the nature and mechanism of the clock is not known, the most accepted hypothesis is an innate clock of biochemical nature, which is able to produce a free running rhythm independent of the external environment.

Lunar-related rhythms have been studied less than circadian rhythms, but there is good evidence for the existence of such rhythmicity in marine animal species (for reviews, see Büning 1973, Palmer 1974, 1975, Neumann 1981, Brady 1982). The majority of the evidence concerns tidal rhythms in invertebrates. In the brown alga 


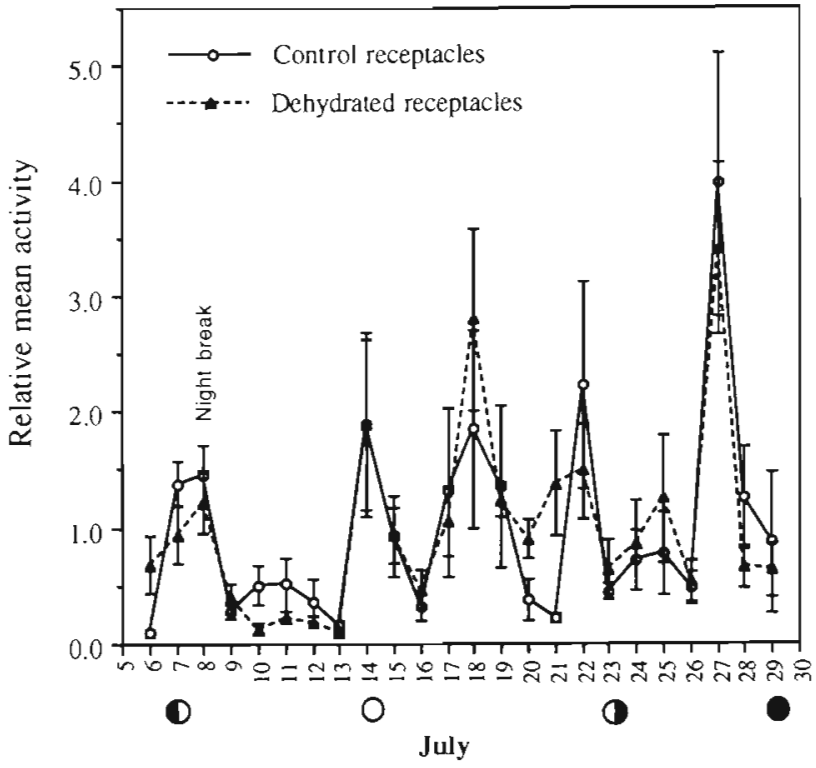

Fig. 3. Fucus vesiculosus. Mean ( $\pm \mathrm{SE}$ ) relative reproductive activity $\mathrm{d}^{-1}$ in control and dehydrated receptacles under constant laboratory conditions of $11^{\circ} \mathrm{C}$ and a light:dark cycle of 17:7 h. Phases of the moon are indicated

Dichtyota dichotoma (Huds.) Lamour., there is a circadian rhythm in egg release and also a fortnightly rhythm, which can be induced under laboratory conditions by light given during the light: dark cycle (Müller 1962, Vielhaben 1963). The period of 14 to $16 \mathrm{~d}$ continues for many months but is changed if the normal $24 \mathrm{~h}$ daylength is shortened or lengthened. From this it has been postulated that the endogenous rhythm in $D$. dichotoma is due to coincidence of certain phases of the $24 \mathrm{~h}$ rhythm, set by the light:dark cycle, and a $12.4 \mathrm{~h}$ tidal rhythm. It should be noted that the basic period of the clock is not known and there is evidence suggesting that an underlying $24.8 \mathrm{~h}$ basic period controls the tidal rhythms; see Palmer (1974).

As for periodicity in fucoid species, Brown et al. (1954) found a tidal rhythm with a daily component in oxygen consumption in Fucus vesiculosus and Brawley (1992) reported on a semilunar cyclic gamete release with a maximum at daytime high tides in F. ceranoides. The timing of gamete release at high salinities in the estuarine environment where $F$. ceranoides was growing resulted in a reduced frequency of polyspermic eggs and a higher successful reproduction (Brawley 1992).

The experiments reported here show that the fortnightly peaks in reproductive activity in Fucus vesiculosus, which were first observed under atidal, constant light and temperature conditions (pers. obs.), are also present under natural conditions in the Baltic Sea. A relatively small number of eggs were shed about the same time every day, revealing a daily cycle, while peaks of released eggs were observed at fortnightly intervals. At present, the cause of this pattern can only be speculated upon. One explanation of the fortnightly interval might be a gravity-entrained bimodal lunar month rhythm with an underlying, moonlight-sensitive cycle. In natural habitats, gravity and moonlight are nearly in phase, which should result in an unambiguous entrainment but, considering the not uncommon situation of cloud cover, gravity should be a more reliable entraining factor. Another possibility might be an interaction of a $24 \mathrm{~h}$ and a $12.4 \mathrm{~h}$ rhythm, as is postulated in the case of Dictyota dichotoma. The interaction of these 2 rhythms might result in peaks of activity at intervals of 15 to $16 \mathrm{~d}$ but also, at about 7 to $8 \mathrm{~d}$ intervals, the 2 cycles are close enough to produce the small bursts of activity which were found in the laboratory experiment. From several experimental results, the endogenous clock is thought to exist on a cellular level (see Palmer 1974) and the slight phase deviation needed for the rhythms to coincide on these 'close' occasions is likely to be present in some cells, due to microhabitat differences. The accidental interruption of the dark period on 8 July might have caused an alteration in the normal pattern, dividing the expected 'full moon peak' on 12 July into 2 lower peaks on 14 and 18 July, respectively. Except for 1 occasion, minor peaks were not observed in the field, but, as amplitude declines, 'noise' becomes difficult to separate from low peaks and further investigations are needed.

Although the results reported in our study suggest the action of an endogenous timekeeper, this is still to be proved. In the laboratory, the daily cycle was observed under a long day light:dark regime of $17: 7 \mathrm{~h}$, which mimics the natural light conditions during the reproductive period, and under which the field experiments were carried out. To prove the presence of a light-entrained circadian clock, a free running period in continous light and a phase shift in response to a changed light:dark regime must be shown.

In lunar-related rhythms, the entrainment can be expected to be produced by some environmental factor following from the rising and falling of the tides (Palmer 1974). Therefore, constant laboratory conditions mean that the studied organism is not exposed to variation in the physiochemical aspects of the tide. In this sense, the criterion of persistence under constant conditions is fulfilled for the observed fortnightly cycle of major egg release, indicating a lunar-related biological clock. However, an interval of 14 to $15 \mathrm{~d}$ was found in the laboratory in 1991 and also in the field experiments in 1992 and it is therefore a matter of guesswork whether or not this interval should be regarded as an entrained or a free running period. In the Baltic Sea, the tidal variation in water level is only a few $\mathrm{cm}$ 
(Kautsky 1988) and this slight variation is masked by irregular fluctuations caused by changing barometric pressure. Therefore, there are no predictable changes during a lunar month (for example in hydrostatic pressure, periodic immersion, carbon dioxide availability or some other tide-induced environmental variation) that might explain the need or existence of a lunar-related clock, or act as an entrainer of the period. Nevertheless, for the entire experimental period the eggs were released $2 \mathrm{~d}$ before full and new moon. A free running period can probably not be expected to show such accuracy. Therefore, the exactness of the intervals suggests either an entrained period or external causes of rhythmicity. However, the periodicity does not seem to be affected by irregular variations in temperature which, in addition to the persistence of the period under constant conditions, points in favour of an endogenous timekeeper.

There are primarily 2 environmental factors which might act as the entrainer of an endogenous lunarrelated rhythm in the absence of tides: the light of the moon, and gravity. Although the slight change in gravity which arises at full and new moon is not manifested in the height of tide, it is nevertheless present in the Baltic Sea, as well as in the laboratory. In case of an interaction between a $12.4 \mathrm{~h}$ rhythm sensitive to gravity (and moonlight), and a light-entrained 24 h rhythm, the agreement in light:dark regime in the laboratory and the field experiment should make a similar period likely.

An organism is usually considered to benefit from internal timekeeping by being adapted to regular and predictable changes in the environment (Palmer 1975, Sweeney 1983, Salisbury \& Ross 1985). Thus, a synchronization of egg release on daytime high tides as was shown for Fucus ceranoides (Brawley 1992) may be the factor restricting this species to estuarine environments with periodic higher salinities. In other dioecious species however, such as $F$. vesiculosus, the primary selective advantage from a biological clock might be not synchronization with the abiotic environment, but synchronization of gamete release within a population. Combined, the fortnightly and the daily rhythms will lead to the recurrent, simultaneous presence of large numbers of male and female gametes in the water mass. This should increase the probability of egg fertilization. The selective value of this aspect should be dependent on other factors which influence the reproductive result of a 'wrong time' gamete liberation. One such factor should be the size and density of the $F$. vesiculosus stand, i.e. the probability of finding a mate with the same phase deviation within the population. Also, as a consequence of the periodicity, the reproductive period of $F$. vesiculosus in the Baltic Sea, which was believed to be about $2 \mathrm{mo}$, is in fact restricted to a few days, mainly before full and new moon. This should be taken into account in discussions concerning environmental management. The basis for forming a judgement about effluents should include not only the kind and amount of a pollutant but also the time for pollutant discharges.

The processes of fertilization and germination seem to be very sensitive to pollution (Andersson unpubl. data) and, especially during the peak of the reproductive season, even a single, momentary pollution event might cause severe damage to the recruitment of Fucus vesiculosus if the discharge of a toxic substance occurs before full or new moon. Further, the increased nutrient load in the Baltic Sea has reduced the amount of free space for recruitment since large areas are today covered by fast-growing filamentous algae (see Kautsky et al. 1992). These factors in combination with the restricted time period of gamete release will severely reduce the possibility of a successful recruitment of $F$. vesiculosus in an area.

Acknowledgements. We thank Prof. J. D. Palmer for valuable comments on an earlier version of the manuscript. Field assistance from Camilla Kautsky is gratefully acknowledged. The study was financially supported by the Hierta Retzius Foundation, the Swedish Environment Protection Agency and the Swedish Natural Science Research Council.

\section{LITERATURE CITED}

Andersson, S., Kautsky, L., Kautsky, N. (1992). Effects of salinity and bromine on zygotes and embryos of Fucus vesiculosus from the Baltic Sea. Mar. Biol. 114: 661-665

Bäck, S., Collins, J. C., Russell, G. (1991). Aspects on the reproductive biology of Fucus vesiculosus from the coast of SW Finland. Ophelia 34: 129-141

Bacon, L. C., Vadas, R. L. (1991). A model for gamete release in Ascophyllum nodosum (Phaeophyta). J Phycol. 27. $166-173$

Brady, J. (1982). Biological timekeeping. University Press, Cambridge

Brawley, S. H. (1992). Fertilization in natural populations of the dioecious brown algae Fucus ceranoides and the importance of polyspermy block. Mar. Biol. 113: 145-157

Brawley, S. H., Johnson, L. E. (1992). Gametogenesis, gametes and zygotes: an ecological perspective on sexual reproduction in the algae. Br. Phycol. J. 27: 233-252

Brown, F. A. Jr, Sandeen, M. I., Webb, H. M. (1954). Solar and lunar rhythms of $\mathrm{O}_{2}$ consumption in the seaweed Fucus. Biol. Bull. 107: 306

Büning, E. (1973). The physiological clock. Springer-Verlag. Berlin, p. 177-186

Burr, F. A., West, J. A. (1970). Light and electron microscope observations on the vegetative and reproductive structures of Bryopsis hypnoides. Phycologia 9: 17-36

Carlsson, L. (1990). Effects of biotic and abiotic factors on the accumulation of radionuclides in Fucus vesiculosus $\mathrm{L}$ Ph.D. thesis, Lund University

Christie, A. O., Evans, L. V. (1962). Periodicity in the liberation of gametes and zoospores of Enteromorpha intestinalis Link. Nature 193: 193-194 
Haage, P. (1975). Quantitative investigations of the Baltic Fucus belt macrofauna 2. Quantitative seasonal fluctuations. Contr. Askö Lab., Univ. Stock. 9: 1-88

Jaffe, L. F. (1954). Stimulation of the discharge of gametangia from a brown alga by a change from light to darkness Nature 174: 743

Jansson, A.-M., Kautsky, N. (1977). Quantitative survey of hard bottom communities in a Baltic archipelago. In: Keegan, B. F., O'Ceidigh, P., Boaden, P. J. S. (eds.) Biology of benthic organisms. Pergamon Press, New York, p. $359-366$

Kalvas, A., Kautsky, L. (1993). Geographical variation in Fucus vesiculosus morphology in the Baltic and North Seas. Eur. J. Phycol. 28: 85-91

Kangas, P., Autio, H., Hällfors, G., Luther, H., Niemi, \&., Saalema, H. (1982). A general model of the decline of Fucus vesiculosus at Tvärminne, south coast of Finland in 1977-81. Acta bot. fenn. 118: 1-27

Kautsky, H. (1988). Factors structuring rocky-and mixed-substratum communities in the Baltic Sea. In: Factors structuring phytobenthic communities. Ph.D. thesis, Stockholm University

Kautsky, H. (1992). The impact of pulp mill effluents on phytobenthic communities in the Baltic Sea. Ambio 21(4): $308-313$

Kautsky, H., Kautsky, L., Kautsky, N., Kautsky, U., Lindblad, C. (1992). Studies on the Fucus vesiculosus community in the Baltic Sea. Acta Phytogeogr. Suec. 78: 33-48

Kautsky, N., Kautsky, H., Kautsky, U., Waern, M. (1986). Decreased depth penetration of Fucus vesiculosus (L) since the $1940 \mathrm{~s}$ indicates eutrophication of the Baltic Sea. Mar. Ecol. Prog. Ser. 28: 1-8

La Claire, J. W., West, J. A. (1978). Light and electron-microscope studies of growth and reproduction in Cutleria (Phaeophyta). I. Gametogenesis in the female plant of $C$. hancockii. Protoplasma 97: 93-110

Lindvall, B. (1984). The condition of a Fucus vesiculosus community in a polluted archipelago area on the east coast of Sweden. Ophelia Suppl. 3: 147-150

Lüning, K. (1981). Egg release in gametophytes of Laminaria saccharina, induction by darkness and inhibition by blue light and UV. Br. Phycol. J. 16: 379-393

This article was submitted to the editor
Mäkinen, A., Haahtela, J., Ilvessalo, H., Lehto, I. (1984). Changes in littoral rocky shore vegetation in the Seili archipelago, SW Finland. Proc. 8th BMB Symp., Lund, Sweden, Aug. 10-14, 1983. Ophelia 3 (Suppl.): 157-166

Müller, D. G. (1962). Über jahres- und lunarperiodische Erscheinungen bei einigen Braunalgen. Botanica mar. 4: $140-155$

Neumann, D. (1981). Tidal and lunar rhythms. In: Aschoff J. (ed.) Handbook of behavioral neurobiology, Vol. 4 Plenum Press, New York, p. 351-380

Palmer, J. D. (1974). Biological clocks in marine organisms. Wiley-Interscience, New York

Palmer, J. D. (1975). Biological clocks of the tidal zone. Scient. Am. 232(2): 70-79

Pringle, J. D. (1986). Swarmer release and distribution of lifecycle phases of Enteromorpha intestinalis (L.) (Chlorophyta) in relation to environmental factors. J. exp. mar. Biol. Ecol. 100: $97-111$

Rönnberg, O. (1984). Recent changes in the distribution of Fucus vesiculosus L. around the Aland Islands (N. Baltic). Ophelia 3 (Suppl.): 189-193

Salisbury, F. B., Ross, C. W. (1985). Plant physiology, 3rd edn. Wadsworth Publishing Company, Belmont, CA

Smith, G. M. (1947). On the reproduction of some Pacific coast species of Ulva. Am. J. Bot. 31:80-87

Sweeney, B. M. (1977). Chronobiology (circadian rhythms). In: Smith, K. C. (ed.) The science of photobiology. Plenum Press, New York, p. 209-226

Sweeney, B. M. (1983). Biological clocks - an introduction. BioSci. 33(7): 424- 425

Sweeney, B. M. (1987). Rhythmic phenomena in plants. Academic Press, New York

Umamaheswara, R. M., Kaliaperumal, N. (1987). Diurnal periodicity of spore-shedding in some red algae of Visakhapatnam coast. J. exp. mar. Biol. Ecol. 106: 193-199

Vielhaben, V (1963). Zur Deutung des semilunaren Fortpflanzungzyklus von Dictyota dichotoma. Z. Bot. 51: $156-173$

Ziegler Page, J., Kingsbury, J M. (1968). Culture studies on the marine green alga Halicystis parvula - Derbesia tenuissima. II. Synchrony and periodicity in gamete formation and release. Am. J. Bot. 55: 1-11

Manuscript first received: December 6, 1993

Revised version accepted: April 27, 1994 